\title{
Translation as a means of interpersonal and interethnic communication
}

\author{
Natalija Koljada - Svetlana Kowalskaia - Ashhen Melkonyan
}

DOI: 10.18355/XL.2019.12.02.07

\begin{abstract}
The article is a review of different approaches to communication issues. It shows the current significance of communication and emphases the role of translation in the process of communication. Materials are devoted mostly to the influence of translated literature on the development of nations. Different versions of translated text may have a different effect on personality when it takes shape. As translation carries communicative and educational functions, different versions of translated text may also add different flavors to the education and communication process. Aside from this, the primary focus was also laid on to the role of translation in knowledge acquisition and language continuity. Additionally, to communicative and educational functions, the outline puts forward other minor functions of translation, such as to deliver cultural information, to perceive the surrounding reality, to give unique characteristics to personality and to deliver human, social and other values. These purposes are accomplished through cultural and linguistic approaches, with the best experience on the subject. As a powerful means of communication, translation is a multi-level process. The findings show that translation does affect the linguocultural, information, educational and communicative spheres of life.

Key words: communication issue, information flow, communication type, translation function
\end{abstract}

\section{Introduction}

Communication issues become a target of research only in the early XX century. Professionals working in different fields of science (philosophy, sociology, psychology, psycholinguistics, pedagogy, etc.) found the matter compelling. Scientists have interpreted communication, as a phenomenon, for many years and in different ways. The term was understood as a natural way to unite people and interact with God, as an essential of human existence (Gaidenko \& Jaspers, 1978; Lomov, 1979).

Communication was considered a basic form of interaction between people (Reznikov, 1958) and viewed as a tool to exchange ideas and goods (Reznikov, 1958). Various writers saw the process of communication as a process by which people pass down their thoughts and experiences (Vygotsky, 1956). Through communication, people are able to understand others and cooperate with them. The communication process is concerned more with the means of communication and with how parties interact with one another rather than on the reasons behind the communication (Ethics in business communication, 2016; Miller, 2005).

At the turn of XX-XXI centuries, communication issues were on the tip of the tongue due to profound changes that occurred in the system of international relations. By that time, they (relations) gained geo-economic, geopolitical and geogenic character (Features of the modern world, 2016; Gutt, 2014; Nord, 2014). Such a shift took place because of the trends emerging back then in the socio-economic sphere, in politics and culture. 
These trends made a difference not only to the social settings but also to the life of an ordinary individual. With the expansion of cross-border communication, translation became a great deal, meaning mostly the semantic translation (Bassnett, 2013; Hatim, 2014; House, 2014) because word-for-word techniques lose some of the original meaning and readers are unlikely to figure it out.

Moreover, the information flow or the exchange of information through communication makes people modify the existing ways of communication (Peculiarities of communication in the modern world, 2016; Gavrilenko, 2016). They (people) together from an information society with both advantages and disadvantages. The latter led to the emergence and spread of informal forms of communication, filler words and profanity among the younger generation (Ling, Bertel, 2013; McSweeney, 2016; Neumayer, Stald, 2014).

It is no secret that many sociology teachers and psychologists are engaged in the study of problems surrounding the organization of leisure activities and communication among youth (Lewis, 2015). They also have the use of studying the communication difficulties that teenagers face. The attention, in this case, is drawn to written communication, to the culture of communication and communication ethics. The translator's work in many ways defines the language culture. Neologisms they introduce, as well as loanwords, make the target language richer (Firbas, 2013; Munday, 2016).

In the 80 s of the $\mathrm{XX}$ century, scientists have attempted to distinguish between different types of communication, treating communication as a human activity, namely communicative activity. One of the classifications is built on the flow of information between parties. When a sender delivers a message to the receiver but gets nothing flowing back, then he/she is engaged in one-way communication. Through one-way communication, an individual acquires knowledge and experience of the entire human species. However, human interactions are an essential of life; you cannot just sit there with a newspaper in your hands and play science for eternity!

People exchange ideas and interests in two-way communication when two people are involved. Such an activity assumes personality formation and development. The third type of communication is tricky, as it involves multiple parties engaged in intragroup communication. As a modern tool of communication, public communication with feedback from members of different social groups and communities is the case. Thus, communication is said to be a social phenomenon with the purpose of collaboration (Brudnyi, 1975). Recently, communication has been promoted as a dialogue of cultures.

Communication can and should take place though signs. The most common system of signs is language. Today, there are about 7000 languages. The translation aims to overcome the language barriers between people, originating from the need to communicate. In the public context, translation exists to ensure bilingual communication. In this case, translation, much as communication, is a multi-level process.

\section{Results}

Because the translation is a multi-level process, it is carried out in three stages (Cantemir, 1987). Below is the description of each on the example of a Cookbook Translation (for clarity, "From Crook to Cook" may serve a good reference). Warning: the translation is not there! These are only recommendations. 


\section{Level/Stage 1: Literal Translation - Do the Basics, Pass the Content, Make a Linguistic Clay for Further Work}

It is when a translator takes the book and renders the content from one language to another. The goal is to deliver the key information so that readers, who could not understand the language, can easily find the knowledge they are looking for. Even though this does not convey the sense, a translator still needs to know how people understand this or that process or thing. This is when language barriers are broken.

Ex.: Just take any advice, recipe or otherwise and translate it using exactly the same words but in a target language. This is done not to lose or twist any valuable information.

\section{Level/Stage 2: Making Connections - Add Personality, Pass the Idea, Mind the Talking within Characters}

It is when a translator mirrors the relationships between the characters within the text (in our case, between chefs, between ingredients, if the author treats them as living beings, between the author and the reader, etc.). In some cultures, there is a top-down model of communication, so you may want to be careful with that. Nevertheless, it is not a major challenge. If the translator has a text written by a single author, who did an excellent job of adding a "personal touch" to his work, then the translator has to dive into the personality of this author and reflect his communication style, attitudes, and mood in the translation. There are also communication ethics to watch, as they differ between cultures. At this stage, some of the text translated earlier can change as the narration style changes.

Ex.: The author of the "From Crook to Cook" is an extraordinary guy, who has a habit of fawning with the reader and uses honest and straightforward language. There is also wordplay, which is not easy to translate.

\section{Level/Stage 3: Adaptation - Bridge Two Cultures, Add Clarifications, Make the Reader Compare and Learn}

It is when a translator recalls the dialogue of cultures. The goal is to preserve the culturally bound terms and phenomena and to add history behind them so that the reader can learn something new. This works great when the object/process/technique described in the text is not present in the target culture. In other cases, when both cultures have the same thing but call it differently, the translator may use the word that fits better. At this stage, the translator may wish to add notes with the life experience of the author if the fact contains anything culturally specific that might be interesting to learn. By learning new, both cultures blend.

Ex.: There are new dishes, jokes, ingredients that can be not popular in the target culture. There are also different terms for one process between English-speaking countries. There is always a space for contribution.

These stages can be followed in their order. As levels of translation, they can be accomplished all at once due to overlapping that takes place between the levels. On the reader's side, there is the fourth level implying the involvement of serious thought about the entire text and separate elements within it. The details follow below. 
The translation is an activity by performing which a person can come up with new writing techniques that will add to cultural development with a fresh approach. This works for any field of human activity from literature to science.

In the international context, translation from one language to another helps people not only to understand each other but also to build cooperation in the field of science and culture and ultimately strengthen the unity of the world. Considering the latest political quarrels, it feels like good translation is important.

Translation has an unusual effect on interpersonal relationships. As previously stated, communication between the author, the reader and the translator is a distinctive attribute of any good translation. This is an example of the so-called individual communication when these three parties speak to each other. This process also has tops and bottoms in a sense.

To begin with, any book introduces us to the world of beauty, leaving an indelible impression on our senses. Our imagination is our friend and master of the soul; it helps to uncover our spiritual riches. For example, Druzhinin (1987: 55) writes about the vast influence Schiller had on the youth of the previous generation. He called Schiller a quiet friend - if not the master of though - whose thoughts are endowed with good feelings in poetic writing. Thanks to the translations of world literature, people around the globe became acquainted with Paul Eluard, Pablo Antonio Cuadra Shota Rustaveli, Omar Khayyam, and many others.

Getting back on the levels of translation, the aspects from earlier fall within the first level of personal communication, which functions are cognitive (to perceive the surrounding reality) and educational. On the level of content (level 1), translation expands our knowledge about other people's ways, about other countries and continents, about habits and customs. It introduces the unprepared reader into a new world through literature, gives him the idea of unreachable objects and foreign culture, which is sometimes utterly unknown to the reader. This kind of communication is essential to children, who learn the world through great men and their works.

Writings from different countries in translation have a direct influence on our outlook. They not only open the door to other worlds, other images and other times but also teach us to live, to create and to learn from history. World literature broadens our ken, thereby projecting a strong influence on our thinking. On the level of involvement (level 2), translation influences our thinking by forcing us to think, to reflect. This, in turn, influences the culture of speech. A reader learns new expressive, colorful and rich phraseological turnovers alongside interesting-sounding structures. Through reading texts written in a native language or translation, an individual learns the rules and regulations of speech that are necessary for dealing with people. Thus, reading enriches our vocabulary and improves our speech. This falls within the third level of translation - the level of relationships and culture - that refers to communication between individuals.

The educational side of the message delivered in the book is not the last thing in translation. By educating a person through imagery, the book affects him/her morally and aesthetically. It falls within the fourth level of translation as communication between the individual and one's personality. This is the level of self-reflection. In other words, translation has a strong influence on our spiritual development, the formation, and development of aesthetic taste and our understanding of fine things. In cross-cultural communication, various values, aesthetic values specifically, are being re-evaluated. 
The psychological effect of reading in translation is that new material encourages a person to take specific actions, aspires and sparks interest to something. Reading reshapes the personality - changes one's attitude to reality and other people makes it (personality) stronger, decisive and intolerant to injustice.

For a translator, the translation process is an examination of literary language. Many translators believed that they would have to improve their knowledge of the target language. However, it turns out that learning any language means suppressing the dominant native language because it does not serve as a point of contact between the translator and the author. The challenge here is to understand the intended meaning and then deliver it adequately in another language so that the effect of communication between the author and foreign reader was the same as if the reader was a native to the author.

The aforesaid suggests that translation from one language to another is a form of human activity with specific functions.

In international communication, translation from one language to another performs the function of knowledge acquisition, thus promoting both the exchange of spiritual values and the creative collaboration between people throughout the world. Through translation, the world literature and pieces of creativity peculiar to a particular culture become known in the broader world.

Any development relies on what already exists, on experience. In other words, continuity is an attribute of development. The continuity of cultural development refers to the continuous accumulation of achievements, experience, and traditions. In a sense, translation has a function of continuity, as it contributes to the enrichment through cultural exchange.

The cultural function of translation (to deliver cultural information) is seen as to improve the cultural intelligence of people through the cross-cultural interaction.

In interpersonal communication, translation performs both a cognitive function and an educational function - it delivers information about social processes and phenomena, about the surrounding world, and many aspects of life.

In intrapersonal communication, translation carries an individuative function (to give unique characteristics to personality) (Violet, 1985: 256). Thus, it (translation) influences the development of personal aptitudes and inclinations through imagery.

Because translated text can educate people and familiarize them with culturally specific norms of work and lifestyle, one may distinguish a value-delivering function of translation. One may do this upon the condition of drawing a veil over the subversive and socially inappropriate language in translation.

Because the translation is communication, it shares a communicative function (to communicate) with language, which is the system of communication.

As an agent in cross-cultural dialogue, a translator must take into account the features of a target culture for correct phrasing.

\section{Conclusion}

A common language does not exist, despite the utopian attempts to create such. Planned languages appeared, such as Esperanto, Ido, and Interlingua, but they are not popular for many reasons.

The translation shall provide an opportunity for people to communicate if they do not speak different languages, whether it is direct communication or text comprehension. 
Hence, today, the role and significance of the translation industry are not contestable. The translation continues to be a powerful means of communication that influences the development of both the nation and the individual personality.

Thus, the translation works on four levels, and it is done in three stages. Both the levels and the stages were distinguished to ensure the understanding of the text. The first is associated with the second, but a level is something that influences the reader, while a stage is a step, which a translator must take after reading the text influencing him on four different levels. This activity, meaning the translation process or reading (depending on the party dealing with a translation), touches upon three spheres of knowledge:

(1) educational sphere (when delivering/learning scientific information, facts, etc.);

(2) cultural sphere (when disclosing/learning folk and literary traditions);

(3) linguistic sphere (when introducing/learning neologisms and borrowed words).

This article will be a useful addition to the educational guidelines for professional translators.

\section{Bibliographic references}

BASSNETT, S. 2013. Translation studies. Routledge. ISBN: 978-0-415-50670-0

BRUDNYI, A.A. 1975. On the problem of communication. Methodological problems of social psychology. M.: Nauka, pp. 165-172.

CANTEMIR, A.D. 1987. Preface to the "Letters" of Horace. Translation is a means of mutual rapprochement of the peoples. M.: Progress, pp. 29-31.

DRUZHININ, A.V. 1987. Schiller, translated by Russian poets. Translation is a means of mutual rapprochement of the peoples. M.: Progress, $55 \mathrm{p}$.

ETHICS IN BUSINESS COMMUNICATION. 2016. Available online: www.nauroke.in.ru

FEATURES OF THE MODERN WORLD. FEATURES OF COMMUNICATION. 2016. Available online: www.fb.ru

FIRBAS, J. 2013. On the communicative value of the modern English finite verb. Available

online: https://digilib.phil.muni.cz/bitstream/handle/11222.digilib/118003/1_BrnoStudiesEngl ish_03-1961-1_5.pdf

GAIDENKO, P.P. - JASPERS, K. 1978. Man and history in the light of "philosophy of communication". Man and his existence as a problem of modern philosophy, pp. 97-134.

GAVRILENKO, N.N. 2016. Methods to Realize Competence-Building Approach while Teaching Translation. IEJME-Mathematics Education, vol. 11, issue 7, pp. 2151-2161.

GUTT, E.A. 2014. Translation and relevance: Cognition and context. Routledge. ISBN: 9781317640905

HATIM, B. 2014. Teaching and researching translation. Routledge. ISBN: 9781317860273

HOUSE, J. 2014. Translation quality assessment: Past and present. Translation: A Multidisciplinary Approach. Palgrave Macmillan UK, pp. 241-264. ISBN: 978-1-13702547-0

LEWIS, C. 2015. Internet communication among youth: New practices and epistemologies. Handbook of Research on Teaching Literacy Through the 
Communicative and Visual Arts, Volume II: A Project of the International Reading Association, 237. ISBN: 0-8058-5379-0

LING, R. - BERTEL, T. 2013. Mobile communication culture among children and adolescents. The Routledge international handbook of children, adolescents and media, pp. 127-133. ISBN: 978-0-415-78368-2

LOMOV, B.F. 1979. Category of communication and activity in psychology. The problems of philosophy, vol. 8, pp. 34-47.

MCSWEENEY, M.A. 2016. Literacies of Bilingual Youth: A Profile of Bilingual Academic, Social, and TXT Literacies.

MILLER, K. 2005. Communication theories. USA: Macgraw-Hill.

MUNDAY, J. 2016. Introducing translation studies: Theories and applications.

Routledge. ISBN: 9781136326332

NEUMAYER, C. - STALD, G. 2014. The mobile phone in street protest: Texting, tweeting, tracking, and tracing. Mobile Media \& Communication,vol. 2, issue 2, pp. 117-133.

NORD, C. 2014. Translating as a purposeful activity: Functionalist approaches explained. Routledge. ISBN: 9781317642374

PECULIARITIES OF COMMUNICATION IN THE MODERN WORLD. 2016. Available online: www.refdb.ru

REZNIKOV, L.O. 1958. The concept of the word. L.: LGU, 124 p.

SKOMAROVSKY, G.S. 1978. Communication as an activity. The concept of activity in philosophical science, Tomsk, pp. 135-142.

VIOLET, A. 1985. Introduction to the General theory of translation. M.: Higher school, $256 \mathrm{p}$.

VYGOTSKY, L.S. 1956. Thinking and speech. The huts. Psychological research. Problems of psychological development of the child, $519 \mathrm{p}$.

Words: 3216

Characters: 21288 (11,8 standard pages)

Dr. Natalija Koljada

Candidate of Philosophical Sciences

Sub-faculty of German philology

Southern Federal University

Rostov on Don, Russia

Russia

natakoljadanata@gmail.com

Dr. Svetlana Kowalskaia

Candidate of philological sciences

Senior lecturer

Sub-faculty of German philology

Southern Federal University

Rostov on Don, Russia

Russia

swetlana-sk@yandex.ru

Dr. Ashhen Melkonyan

Candidate of Pedagogic Sciences

Senior lecturer

Sub-faculty of German philology 
Southern Federal University

Rostov on Don,

Russia

ashchen@yandex.ru 